\title{
Linking Employee Resilience with Organizational Resilience: The Roles of Coping Mechanism and Managerial Resilience
}

\section{Fu Liang \\ Linlin Cao}

School of Business Administration, Shandong University of Finance and Economics, Jinan, People's Republic of China
Correspondence: Linlin Cao Email cll202I@I63.com
Background: Environmental uncertainty has become the normal surviving and development environment for organizations. Resilience is the key to manage the crisis and abrupt crush, and the relationship between employee resilience and organizational resilience still needs to be explored in Chinese context. The study is to uncover the black box between employee resilience and organizational resilience.

Methods: Based on the conservation of resource theory, this study introduced managerial resilience, problem-focused coping and emotion-focused coping into the relational mechanism between employee resilience and organizational resilience. The study adopted structural equations, bootstrapping methods, and analyzed 329 multi-point employee-manager matching data as the research basis from high-tech industries, service industries, and traditional manufacturing industries.

Results: This study demonstrated that employee resilience is positively associated with organizational resilience; The indirect effects of employee resilience on organizational resilience through problem-focused coping and emotion-focused coping were statistically significant; moreover, managerial resilience positively moderated the relation between employee resilience and emotion-focused coping, and it also moderated the indirect effect of employee resilience on organizational resilience through emotion-focused coping.

Conclusion: This study adds value to the literature by revealing employee resilience boots problem-focused coping and emotion-focused coping, resulting in more or less organizational resilience in the context of Chinese enterprises. It is suggested that in the daily management of the organization, we should pay more attention to cultivate and develop employee resilience to improve organizational resilience.

Keywords: employee resilience, managerial resilience, problem-focused coping, emotionfocused coping, organizational resilience

\section{Introduction}

Organization are systems that operate in a dynamic and changing environment. ${ }^{2}$ Driven by the wave of digital technology, the global economic environment has become more complex and changeable. ${ }^{3}$ In the VUCA era of volatile, uncertain, complex and ambiguous, "black swan" and "grey rhino" incidents caused by weather disasters, geopolitics, pandemic outbreaks, scientific and technology innovation and other non-human control factors happened frequently, which brought huge impacts to global enterprises, just like the destruction, interruption and setbacks caused by the sudden outbreak of COVID-19 in 2020, even the top 
companies with strong economic strength are inevitably suffer heavy losses. ${ }^{4}$ Spencer Johnson emphasized that "the only constant is change, we must learn to adapt and respond to change". When change becomes the new normal, resilience becomes a new skill for corporate survival and sustainable development, helping companies to quickly recover from emergencies. Enterprises need to improve organizational resilience so that they can cope with emergencies and make full use of crisis events that may threaten the organization, ${ }^{5}$ the organization can recover from shocks to a balanced state, survive adversity, and even develop new abilities and achieve breakthrough growth. ${ }^{6,7}$ Confirmed that organizational resilience can help companies live longer by improving their ability to resist and adapt to environmental changes. Therefore, how to promote the construction and improvement of organizational resilience has become the key to the sustainable development of the current organization.

In view of the importance of organizational resilience, scholars have explored organizational resilience from different fields and perspectives. In the current study, research on the definition of organizational resilience has not yet reached a consensus, among which the dynamic capability perspective, ${ }^{8}$ the resource perspective and the ecosystem perspective ${ }^{9}$ are particularly common. Scholars have extensively explored the impact of individual psychological capital, ${ }^{10}$ social capital, ${ }^{11,12}$ entrepreneurial resilience $^{13,14}$ on organizational resilience, ${ }^{15}$ proposed that this dynamic capability should be studied from three different levels: individuals, groups, and organizations, and the impact mechanism of employee resilience on organizational resilience has been in the initial stage of research.

Furthermore, employee resilience is a variable of individual differences. It is not only a unique component of an individual's personality, but also an individual's dynamic ability to use the protective resources in the organization and the environment to interact dynamically with the environment to accomplish goals and achieve their own growth. ${ }^{16}$ Employee resilience can enhance organizational resilience, but why and how it affects organizational resilience still need to be further explored.

The existing research mainly focused on the organizational level, ${ }^{17}$, leadership characteristics, ${ }^{1,18}$ and employee characteristics $^{10,19}$ and other multi-level and multiperspective analysis of the mechanism of organizational resilience. Although there are many studies that have made useful attempts on the antecedents of organizational resilience, studies that focus on the promotion or hindrance of employee resilience to organizational resilience still need to be further explored. On the one hand, existing studies have shown that employee psychological capital, social capital, etc. can trigger happiness, coping and affect organizational resilience, and employee resilience is an important part of employee psychological capital, which should have a certain impact on organizational resilience $;{ }^{20}$ On the other hand, considering that managers have more power and their personal characteristics have a decisive influence on organizational strategy and decision-making, ${ }^{21}$ studies have explored the influence of managers on different organizational outcome indicators, including entrepreneurship intention, ${ }^{22}$ business success. ${ }^{23,24}$ Therefore, there are good reasons to infer that managerial resilience may interact with employee resilience, ${ }^{25}$ thereby acting on organizational resilience. To this end, this paper attempts to incorporate employee resilience, managerial resilience, and employee coping styles into the impact model of organizational resilience from the perspective of multi-level resilience interactions, and answer whether employee resilience can and through which mechanisms affect organizational resilience. It is expected to provide a reference for enhancing organizational resilience and improving organizational management efficiency.

The structure of the paper is as follows. Theoretical background and hypotheses provides the literature review and hypotheses of the paper; The information of sample collecting procedures, measures of the variables are provided in research method; Results show the descriptive statistics, CFA and hypotheses testing; Finally, discussion presents the conclusion, theoretical contribution, practical contribution and the limitations and further directions.

\section{Theoretical Background and Hypotheses Employee Resilience and Organizational Resilience}

Resilience is an emerging field in psychology and organizational behavior. ${ }^{26}$ In this case, resilience is a positive internal resource, and employees can use resilience to deal with turbulence and stress in the workplace. ${ }^{27}$ When effectively developed and managed, resilience can lead to positive personal and organizational outcomes . However, it is necessary to distinguish employee resilience from psychological resilience. The former refers to the employees' 
ability promoted and support by the organization to actively respond, adapt and develop, ${ }^{28}$ it emphasizes the role of the organization in promoting and supporting the development of resilience. ${ }^{26}$

Unlike psychological resilience, employee resilience responds to adversity based on workplace behavior rather than belief in their own abilities. ${ }^{28}$ A resilient workforce can react positively and powerfully in adversity, which is essential for the survival and future prosperity of the organization. $^{29}$ Organizations with resilient employees can thrive, not just survive. They are better able to rebound and learn from adversity and uncertainty. As individuals engage in more work and have more flexible work arrangements, such skills become more and more important. $^{30}$ Therefore, employee resilience should be viewed as a set of skills and attributes that can be developed through appropriate human resource intervention. ${ }^{29}$ For example, social support centered on human development can be used to enhance employee resilience. ${ }^{31}$ In addition to encouraging leaders to provide supportive behaviors, leadership behavior and participation also need to be emphasized. ${ }^{32}$

Organizational resilience refers to the ability of an organization to increase its awareness of the risk environment and reduce its vulnerability, to reformulate business strategies in the face of changes, to constantly understand and adapt to changes, and to proactively react before changes are needed, ${ }^{33}$ and even the ability to create new opportunities and develop new functions. ${ }^{34,35}$ Survival and recovery from adverse conditions are the foundation of this definition. The adaptability of an organization is the core of its resilience. ${ }^{36}$ Organizations should not only respond and adapt to environmental turbulence, but also actively initiate, restore, update and redesign organizational structures and relationships so that they can thrive in adversity. ${ }^{37}$ The three dimensions of organizational resilience have been recognized in the literature, namely, the cognitive dimension, the behavioral dimension, and the contextual dimension., ${ }^{2,38}$ The cognitive dimension of a strong sense of purpose, core values, shared vision, language use, ${ }^{39,40}$ and constructive meaning construction $^{41}$ contribute to the creation of organizational resilience creation. The behavioral dimensions of resource redundancy, agility, useful habits and preparation behaviors in practice combine to generate centrifugal force and centripetal force for the development of organizational resilience ${ }^{5}$ the basic contextual conditions that support resilience include Psychological safety, deep social capital, decentralization of power and responsibilities, and extensive resource networks ${ }^{5}$ depend on the internal and external relationships of the organization to promote effective responses to environmental complexity.

According to Hillmann, ${ }^{42}$ organizational resilience refers to the ability of an organization to maintain its functions and quickly recover from adversity by mobilizing and acquiring required resources. Therefore, organizational resilience is closely related to the resources the organization has. ${ }^{43}$ As one of the most important resources of an organization, human resources will inevitably affect organizational resilience. ${ }^{44}$ Linnenluecke $^{45}$ believes that the resilience of different levels (individual, team, organization) should be further explored how to coordinate with each other and work together to form organizational resilience. $^{6}$ As an important ability for individuals to cope with adversity situations, employee resilience can significantly improve organizational resilience.

First of all, an organization is a system, and employee resilience is an important component of the system. Like the resilience system, when the organization is hit by a crisis event, resilient employees can exert their resilience ability, effectively respond to and absorb disturbances, and help the organization resolve and respond to crises, which can maintain the business functions and constitute the dynamic attributes of the organization; ${ }^{7}$ Secondly, the ultimate executor of organizational strategy is employees. As an important carrier of organizational capabilities, employees' organizational resilience is deeply embedded in employees' psychology and behavior. Resilient employees' individual-level knowledge, skills and abilities can improve employees' adaptability and creative problemsolving ability, which would improve the organization's ability to respond to environmental shocks, and help the organization manage the competitiveness required for organizational resilience; Finally, according to the ASA theory, a team composed of resilient employees can attract individuals with the same characteristics to join the organization. Through the two-way interactive process of attraction-selection-friction, they gather at the organizational level to form a more resilient organization.

Based on this, this article proposes the following hypotheses regarding the relationship between employee resilience and organizational resilience:

H1: Employee resilience has a significant positive impact on organizational resilience. 


\section{Coping Mechanism}

Coping refers to the cognitive and behavioral efforts made by individuals to manage the internal and external needs that exceed people-environment changes and personal resources, ${ }^{46}$ to prevent, eliminate or reduce stressors or to withstand stress at the least cost. The effect reflects the tendency of the coping process. ${ }^{47}$ Coping has two main functions: dealing with problems that cause pain (problem-focused coping) and regulating emotions (emotion-focused coping). The problem-focused coping mechanism is mainly to change the human-environment relationship, change the situation through active interpersonal communication, generate problem-solving strategies, evaluate strategies and work on the steps to solve the problem; ${ }^{48}$ Emotion-focused coping mechanism is the control of stressful emotions or physical arousal, including alienation, self-control, seeking social support, avoidance, rejection, venting, and positive reinterpretation of events. $^{48}$

According to the conservation of resource theory (COR), individuals have the tendency to preserve, protect, and acquire resources. When an organization encounters a crisis or undergoes changes, whether it is a potential threat of resource loss or actual resource loss, it will cause individual tension and pressure. ${ }^{49}$ The conservation of resource theory further emphasizes the priority of loss, that is, the impact of resource loss on individuals is much higher than that of resource acquisition. In view of the fact that response is embedded in employee resilience, it means that employees must actively respond to and adapt to changes to maintain resilience, ${ }^{27}$ and continue to take corresponding actions to protect existing resources from loss. Employee resilience can enable individuals to manage emotional distress, and can also motivate individuals to make quick decisions and take corresponding measures to solve immediate problems, so as to protect existing resources and obtain new resources. Therefore, employee resilience may adopt a problemfocused coping mechanism, because it enables employees to perform a series of actions to deal with emergencies or adversity; it may also adopt an emotional-focused coping mechanism, because it can help employees produce rationalize, detach or avoid problematic emotions to deal with current stressors. Coping reflects the individual's attempts to manage stressors. ${ }^{50}$ The choice of individual coping styles affects the intensity and nature of coping behaviors, and plays a decisive role to the final results.
First, resilient employees have more resources. According to the theory of resource conservation, when employees face resource loss, they will trigger individual emotional and behavioral changes. ${ }^{49}$ Taking corresponding actions to protect, preserve and maintain resources is the most effective way to protect one's own resources or potential resources from loss. Problem-focused coping is to solve the problem as the primary goal, ${ }^{48}$ employee resilience can stimulate employees' inner work enthusiasm and initiative, and provide a strong driving force for employee innovation and creativity, and under the guidance of the organization's strategic goals, it is committed to finding effective ways for the organization's survival and development. Just as what Lin Qingxuan's employees have done, under the impact of the crisis, they are committed to learning new knowledge, integrating knowledge stock, combining new and old knowledge, forming a new knowledge framework, and putting it into practice. Problem-focused coping focuses on changing the existing situation, especially when the organization responds to a crisis or emergency. As defined, the problem-focused coping is aimed at changing the status quo of the organization. Therefore, it will continue to explore feasible solutions, seek alternative business paths, try to promote and optimize existing business processes in new ways, help the organization adapt to changes or adversities, and improve the organization's environmental adaptability, innovation and creativity, which are the keys to organizational resilience. ${ }^{51}$ Secondly, employee resilience helps employees cope with the pressure and turbulence in the organization. Through adequate problem analysis, the current organizational situation is determined, and with the support of the organization, it adopts a problemfocused coping, and is committed to exploring and implementing appropriate strategies to improve organizational decision-making capabilities, which provides the possibility for the organization to quickly return to a balanced state.

Therefore, the problem-focused coping is helpful to the construction and improvement of organizational resilience. Based on the above analysis, we propose the hypotheses:

$\mathrm{H} 2$ :Problem-focused coping positively mediates the relationship between employee resilience and organizational resilience.

Emotion-focused coping tends to regulate the emotions triggered by negative situations and aim to manage 
emotional distress related to the situation. ${ }^{46}$ The range of strategies to focus on emotions is quite wide, including denial, attention and venting of emotions, active reinterpretation of events, and seeking social support. Therefore, it is not surprising that the effectiveness of Emotionfocused coping depends on the specific form of emotional strategy adopted. Employee resilience generally produces appreciable and positive results, which can help employees cope with adversity. Therefore, employee resilience does not tend to choose emotion-focused coping. On the one hand, emotion-focused can be explained by attributing negative conditions to external and temporary reasons (). Individuals spend most of their time and energy on processing and expressing their emotions. ${ }^{48}$ Emotional focus is crucial to the growth and personal well-being of individuals under negative circumstances. ${ }^{52}$ Positive and optimistic emotions can encourage employees to see hope, reduce negative impacts, and may adopt a relatively objective view $^{20}$ to improve the adaptability of employees. However, it cannot directly help the organization find solutions and strategies to solve the difficulties at this stage; on the other hand, the emotion-focused coping can enable employees to passively deal with the setbacks and stressors, and adopt an attitude of avoiding and escaping the problems. Emotion-focused coping shows that employees focus on their own emotional management under adverse circumstances, and focus their attention on panic, anxiety, and frustration against setbacks and changes, such as panic, anxiety, and frustration, that have nothing to do with ability improvement, accurate situational awareness, etc. rather than adopting corresponding strategies to solve problems, which distracts their focus, and does not help the organization to respond to and adapt to crises and changes, reduces organizational creativity and rapid decision-making capabilities, and weakens organizational resilience. In view of this, we hypothesize that:

H3: Emotion-focused coping negatively mediates the relationship between employee resilience and organizational resilience.

\section{Managerial Resilience}

Resilience refers to the ability to adapt and recover in tragedy, trauma and other adversities. ${ }^{53}$ Entrepreneurial resilience is defined as the ability to overcome highimpact challenges and persist in the entrepreneurial process in the face of unfavorable situations and unexpected results. ${ }^{54}$ It is the result of the interaction between the entrepreneur and his environment, and it is an important part of the entrepreneur quality. ${ }^{6}$ This is a dynamic and constantly evolving process through which entrepreneurs can acquire knowledge, abilities and skills, and help solve uncertainty with a positive attitude, creativity and optimism relying on their own resources. In the face of adverse situations, resilient entrepreneurs are not prone to passivity and depression, ${ }^{55}$ they can actively develop and mobilize resources, and constantly adapt to turbulence and environmental changes. ${ }^{56}$

A key aspect of the link between employee resilience and organizational resilience involves human resource management and the role of professionals in promoting employee resilience. Surprisingly, this has received little attention in the literature. Entrepreneurs are the leaders and decision makers of enterprises and have a decisive effect on the survival and development of enterprises. Based on the conceptual characteristics of entrepreneurial resilience, this paper collectively refers to the resilience characteristics of managers such as entrepreneurs, middle-level managers, and first-line managers as managerial resilience. ${ }^{57}$ Managers can promote employee resilience through attitudes, behaviors, policies, etc., ${ }^{25}$ and guide employees to exert their resilience in the face of pressure. If we take an enterprise as an analysis unit, managers play an important role as decision-makers and pass specific culture and values among employees,${ }^{58}$ making an important contribution to enhancing employee resilience and organizational resilience. For managers, the more resilient people are those who will restart when there is a business opportunity or encounter a crisis. ${ }^{59}$ They are not easily frustrated by problems, but can take quick actions and strategies to solve problems.

In view of this, managers who believe that they have the ability to deal with stressful environments and engage in management activities will be able to better build resilience, convey a resilient attitude towards employees, and guide employees to build and exert resilience by sharing knowledge, motivation and common vision, instead of falling into emotion-focused coping style, such as fearing of difficulties, doubting about the future of the organization, considering whether vital interests will be damaged and whether to advance and retreat with the organization.

As the Analects of Confucius goes

when a ruler's personal conduct is correct, his government is effective without giving orders. If his personal conduct is not correct, even he may give orders, but they will not be followed. 
Managerial resilience is a silent encouragement to employees. It motivates employees to advance and retreat together with the organization. By setting tasks, plans, long-term goals and short-term goals for the organization, it provides employees with practical work goals and guides employees to rationally analyze problems and adopt creative strategies to cope with challenges, which are typical characteristics of problem-focused coping style. Therefore, managerial resilience has a certain influence on the performance of employees' resilience. Based on the above, we propose the following hypotheses:

H4: The stronger the managerial resilience, the stronger the positive influence of employee resilience on problemfocused coping style.

H5: The weaker the managerial resilience, the stronger the negative influence of employee resilience on emotionfocused coping style.

Based on the above, the theoretical model is shown in Figure 1.

\section{Research Method Sample Collecting Procedures}

The sample for this study comes from 7 private enterprises and 2 large state-owned enterprises in Shanghai, Hangzhou et al These enterprises are mainly engaged in medical equipment, traditional manufacturing, transportation services, and high-tech industries. The reason for choosing multiple industries for the study is that during the epidemic, China's entire market economy was at a semi-stasis in the short term. Most industries need to break their inherent thinking patterns and flexible work behaviors to help companies get through the critical period. Greater organizational resilience can help companies survive and develop in adversity. In order to ensure the quality of the data, it was divided into three time points to collect data, and the interval between each data collection was 1 month. Since the respondents include middle and high-level managers, we contact the researcher two days in advance each time to negotiate and fill in the questionnaire. At the same time, because we used leader-employee matching data, in order to reduce the researcher's alertness and improve the quality of the data, an anonymous paper questionnaire is used on site, and the matching data is sealed and stored in a file bag. The electronic questionnaire is matched by randomly assigning numbers to the leaders and corresponding employees (the numbers are only known to the leaders and their employees).

In the first wave, employees filled in demographic variables such as gender, educational background, and employee resilience, and 598 employee questionnaires were returned; In the second wave, employees and their corresponding leaders filled out the response mechanism, managerial resilience, and finally obtained 90 leader questionnaires and 497 employee questionnaires; Organizational resilience was filled by employees in the third wave and returned 468 employee questionnaires. After excluding the unqualified questionnaires with serious missing or high repeated data, 61 leaders and 329 employee questionnaires were finally obtained, and the effective response rate was $70.3 \%$.

As was shown in Table 1, of the 329 employee respondents, $37.10 \%$ were female. Employees' age was distributed as follows: 25 years or below (5.8\%),25-35 years (33.1\%),35-45 years (21.9\%),45-60 years (39.2\%). 9.7\% respondents possessed a Master's or higher degree, most of the respondents had a bachelor degree (48.80\%),25.8\% respondents graduated from community college, and $15.5 \%$ respondents possessed a below high school degree. Of the 61 manager respondents, $29.50 \%$ were female. The age was distributed as follows: $25-35$ years $(34.4 \%), 35-$ 45 years $(64.1 \%), 45-60$ years $(11.5 \%)$.

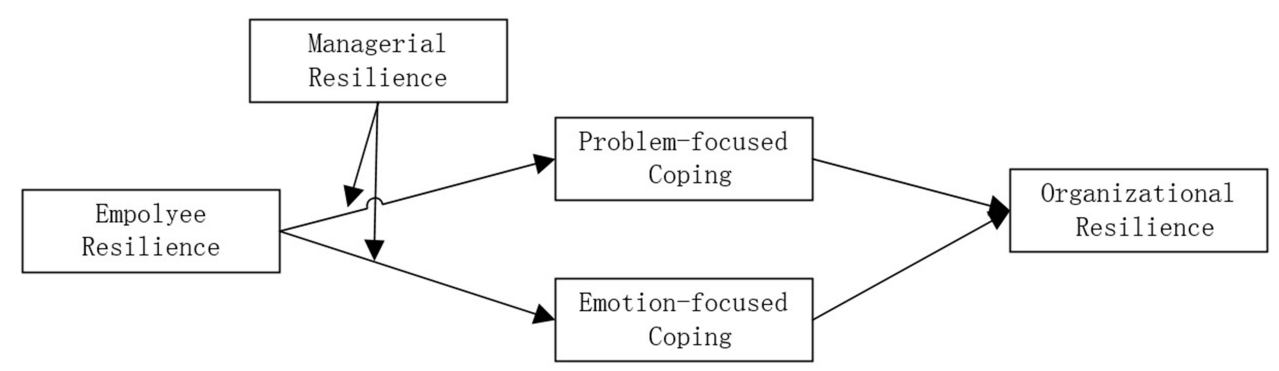

Figure I Theoretical Model. 
Table I Basic Information

\begin{tabular}{|c|c|c|c|c|c|c|c|}
\hline \multicolumn{4}{|c|}{ Managers } & \multicolumn{4}{|c|}{ Employees } \\
\hline \multicolumn{2}{|c|}{ Statistical Variables } & \multirow{3}{*}{$\begin{array}{l}\mathbf{N} \\
18 \\
43\end{array}$} & \multirow{3}{*}{$\begin{array}{l}\text { Rate } \\
29.5 \% \\
70.5 \%\end{array}$} & \multicolumn{2}{|c|}{ Statistical Variables } & \multirow{3}{*}{$\begin{array}{l}\mathbf{N} \\
122 \\
207\end{array}$} & \multirow{3}{*}{$\begin{array}{l}\text { Rate } \\
37.1 \% \\
62.9 \%\end{array}$} \\
\hline Sex & Female & & & Sex & Female & & \\
\hline & Male & & & & Male & & \\
\hline \multirow[t]{3}{*}{ Posi } & H-Manager & 31 & $50.8 \%$ & \multirow[t]{4}{*}{ Age } & Lower than 25 years & 19 & $5.8 \%$ \\
\hline & M-Manager & 24 & $39.3 \%$ & & $25-35$ years & 109 & $33.1 \%$ \\
\hline & F-Manager & 6 & $9.8 \%$ & & $35-45$ years & 72 & $21.9 \%$ \\
\hline \multirow[t]{3}{*}{ Age } & $25-35$ years & 21 & $34.4 \%$ & & $45-60$ years & 129 & $39.2 \%$ \\
\hline & $35-45$ years & 33 & $64.1 \%$ & \multirow[t]{5}{*}{ Edu } & Master's or higher degree & 32 & $9.7 \%$ \\
\hline & $45-60$ years & 7 & $11.5 \%$ & & Bachelor's degree & 161 & $48.9 \%$ \\
\hline \multirow[t]{3}{*}{ Edu } & Master's or higher degree & 14 & $23.0 \%$ & & Community college & 85 & $25.8 \%$ \\
\hline & Bachelor's degree & 40 & $65.6 \%$ & & Below high school degree & 51 & $15.5 \%$ \\
\hline & Community college & 14 & $11.5 \%$ & & & & \\
\hline
\end{tabular}

\section{Measures}

We adopted multi-items scales used in prior research to measure all the variables in the study (As is shown in the Appendix I). Respondents were asked to fill the questionnaire with Likert- 5 scales [ $1=$ strongly disagree, $5=$ strongly agree), the details were explained below.

\section{Employee Resilience}

We used six items to check employee resilience developed by, ${ }^{60}$ which included items such as "I usually take stressful things at work in stride". The internal consistency reliability was 0.876 .

\section{Managerial Resilience}

Managerial resilience was measured by using four items from, ${ }^{61}$ which included items such as "I look for creative ways to alter difficult situations". The internal consistency reliability was 0.943 .

\section{Coping Mechanism}

We used five items from Kim (2020), ${ }^{62}$ Kluger and DeNisi $(1996)^{63}$ to measure problem-focused coping, which included items such as "The emergence of the crisis helps me pay more attention to how I solve the problem". The internal consistency reliability was 0.891 . Emotionfocused coping was assessed by eleven items from, ${ }^{64}$ which included items such as "Try to forget the crisis and refuse to think too much". The internal consistency reliability was 0.842 .

\section{Organizational Resilience}

Organizational resilience was assessed by planned and adaptive capacity from, ${ }^{37}$ which included ten items such as "Given how others depend on us, the way we plan for the unexpected is appropriate". The internal consistency reliability was 0.908 .

\section{Control Variables}

We controlled employees' and leaders' demographic variables including sex, age and education.

\section{Results}

\section{Descriptive Statistics}

Table 2 presents the descriptive statistics used in the survey, including means, standard deviations, and Pearson correlations. The results show that employee resilience was positively associated with organizational resilience $(\mathrm{r}=0.523, \mathrm{p}<0.01]$ and problem-focused coping $(\mathrm{r}=0.485$, $\mathrm{p}<0.01$ ), and negatively related with emotion-focused coping $(\mathrm{r}=-0.330, \mathrm{p}<0.01)$. Emotion-focused coping was negatively associated with organizational resilience $(r=$ $-0.342, \mathrm{p}<0.01)$. The results laid a basis to our hypotheses.

\section{Confirmatory Factor Analysis(CFA)}

We tested for common method bias by Harman one factor test, and it explains $68.4 \%$ of the total variation, more than $60 \%$, and the first factor explains $31.0 \%$ of the total variation, less than $50 \%$, indicating that the homologous variance of the data is within an acceptable range. The overall $\mathrm{KMO}$ value is 0.919. The statistics of the Bartlett test are significant at the 
Table 2 Means, Standard Deviations and Correlations of Independent and Dependent Variables

\begin{tabular}{|l|c|c|c|c|c|c|}
\hline Var & M & SD & I & $\mathbf{2}$ & $\mathbf{3}$ & $\mathbf{4}$ \\
\hline I Employee Resilience(ER) & 3.499 & 0.691 & & & \\
2 Managerial Resilience(MR) & 3.598 & 0.932 & $-0.26 I^{* *}$ & & \\
3 Problem-Focused(PF) & 3.657 & 0.738 & $0.437^{* *}$ & $-0.150^{*}$ & \\
4 Emotion-Focused(EF) & 2.573 & 0.699 & $-0.310^{* *}$ & $0.48 I^{* *}$ & $-0.26 I^{* *}$ & \\
5 Organizational Resilience(OR) & 3.645 & 0.611 & $0.518^{* *}$ & $-0.296^{* *}$ & $0.699^{* *}$ & $-0.330^{* *}$ \\
\hline
\end{tabular}

Notes: Control variables were not included; ${ }^{*} \mathrm{p}<0.05$, ${ }^{*} \mathrm{p}<0.01$ (two-tailed test).

level of less than $0.001 \%$, indicating that it is suitable for factor analysis. On this basis, the validity analysis was further tested by using Mplus7.4. According to Tables 2 and 3, all coefficients are less than the square root of AVE, it indicates that the discriminant validity is good enough; According to Table 3, all the CRs, AVEs are more than 0.5, it demonstrates that the convergent validity is good enough.

To examine the construct validity of our measurement model, we conducted confirmatory factor analysis with Mplus7.4. First, we evaluated the measurement model that contained all five latent variables (employee resilience, managerial resilience, problem-focused coping, emotion-focused coping and organizational resilience). The results were shown in Table 4 and the results indicated that our measurement model fitted the better with $\chi^{2}=878.275, \quad \mathrm{DF}=395, \quad \chi^{2} / \mathrm{df}=2.223<3$, CFI $=0.906>0.9, \quad$ TLI $=0.897, \quad$ RMSEA $=0.061<0.8$, SRMR $=0.061<0.8$ than other measurement models with different latent variables. All the factors related to the proposed constructs were significant and supported the convergent validity.

\section{Hypotheses Testing}

We constructed structural equal with Mplus7.4 to test our hypotheses. After controlled the sex, age, education of employees and managers, employee resilience was positively related to organizational resilience $(\beta=0.593, p<$ 0.001). Hypothesis 1 was supported.

The mediating effect was tested by bootstrapping. The results were shown in Table 5. Employee resilience was positively associated with problem-focused coping ( $\beta=$ $0.324, p<0.001$ ), problem-focused coping was positively related to organizational resilience $(\beta=0.789, p<0.001)$, and the mediating role of problem-focused coping is significant (mediating effect value $=0.255, \mathrm{p}<0.001$ ). The $95 \%$ CI is $[0.154,0.376]$, which not include 0 , indicating that problem-focused coping partly mediated the relationship between employee resilience and organizational resilience.

Similarly, employee resilience was negatively associated with emotion-focused coping ( $\beta=-0.279$, $\mathrm{p}<0.001$ ), emotion-focused coping was negatively related to organizational resilience $(\beta=-0.197, p<0.01)$, and the mediating role of emotion-focused coping was significant

Table 3 Analysis of Factors

\begin{tabular}{|l|c|l|c|c|c|}
\hline Var & Item & Factor Loading & CR & AVE & Square Root of AVE \\
\hline Employee Resilience(ER) & 6 & $0.573 \sim 0.839$ & 0.865 & 0.521 & 0.722 \\
Managerial Resilience(MR) & 4 & $0.820 \sim 0.943$ & 0.929 & 0.765 & 0.875 \\
Problem-Focused(PF) & 4 & $0.775 \sim 0.867$ & 0.892 & 0.673 & 0.820 \\
Emotion-Focused(EF) & 11 & $0.636 \sim 0.763$ & 0.917 & 0.503 & 0.709 \\
Organizational Resilience(OR) & 10 & $0.644 \sim 0.821$ & 0.928 & 0.565 & 0.752 \\
\hline
\end{tabular}

Table 4 Results of CFA

\begin{tabular}{|l|c|c|c|c|c|c|c|}
\hline Model & $\chi \mathbf{2}$ & DF & $\chi \mathbf{2}$ / df & CFI & TLI & RMSEA & SRMR \\
\hline Five-factor model:ER, EnR, PF, EF, OR & 878.275 & 395 & 2.223 & 0.906 & 0.897 & 0.061 & 0.061 \\
Four-factor model:ER, EnR, PF + EF, OR & 1492.275 & 399 & 3.740 & 0.788 & 0.769 & 0.091 & 0.111 \\
Three-factor model:ER + EnR, PF + EF, OR & 2599.639 & 402 & 6.467 & 0.574 & 0.539 & 0.129 & 0.130 \\
Two-factor model:ER + EnR + PF + EF, OR & 2969.661 & 404 & 7.351 & 0.502 & 0.464 & 0.139 & 0.130 \\
One-factor model:ER + EnR + PF + EF + OR & 3097.376 & 405 & 7.648 & 0.478 & 0.439 & 0.142 & 0.137 \\
\hline
\end{tabular}


Table 5 The Testing Results of the Mediating Role of ProblemFocused and Emotion-Focused Coping

\begin{tabular}{|l|l|l|l|l|l|l|}
\hline \multirow{2}{*}{ DV } & \multirow{2}{*}{ MV } & \multirow{2}{*}{ Type } & \multirow{2}{*}{ EST } & \multirow{2}{*}{ SE } & \multicolumn{2}{|c|}{$95 \%$ Cl } \\
\cline { 5 - 7 } & & & & & LCI & HCI \\
\hline \multirow{2}{*}{ OR } & \multirow{2}{*}{$\mathrm{PF}$} & Indirect & 0.255 & 0.057 & 0.154 & 0.376 \\
& & Direct & 0.153 & 0.066 & 0.013 & 0.276 \\
& & Total & 0.408 & 0.07 & 0.263 & 0.539 \\
\cline { 3 - 7 } & \multirow{2}{*}{$\mathrm{EF}$} & Indirect & 0.054 & 0.023 & 0.019 & 0.106 \\
& & Direct & 0.564 & 0.062 & 0.423 & 0.669 \\
& & Total & 0.618 & 0.058 & 0.491 & 0.710 \\
\hline
\end{tabular}

(mediating effect value $=0.054, \mathrm{p}<0.05$ ). The $95 \% \mathrm{CI}$ is $[0.019,0.106]$, which not included 0 , demonstrating that emotion-focused coping mediated the relationship between employee resilience and organizational resilience. Hypothesis 2 and hypothesis 3 were supported.

Finally, we turn our attention to hypothesis 4. stipulating managerial resilience moderates the relationship between employee resilience and two different coping styles. The moderating role of managerial resilience on the relationship between employee resilience and problemfocused coping was insignificant $(\beta=-0.114, p>0.05$ ). The interaction between employee resilience and managerial resilience was negative and significant $(\beta=-0.110, \mathrm{p}<$ $0.05)$,indicating that managerial resilience moderated the relationship between employee resilience and emotionfocused coping. Hypothesis 4 was not supported, and Hypothesis 5 was supported.

To clearly demonstrate the moderating effect of managerial resilience, we follow the method of Aiken and West (1991), ${ }^{65}$ and the results are shown in Table 6. Two groups were divided based on the value of managerial, where higher managerial resilience was one standard deviation above the mean of and lower managerial resilience was one standard deviation below the mean. The bootstrapping result was visible in the group of high managerial resilience, and difference between the two groups is significant, managerial resilience had a negative effect on emotion-focused coping

Table 6 The Moderating Role of Managerial Resilience

\begin{tabular}{|l|l|l|l|l|l|l|}
\hline \multirow{2}{*}{ DV } & \multirow{2}{*}{ MV } & \multirow{2}{*}{ Level } & \multirow{2}{*}{ EST } & \multirow{2}{*}{ SE } & \multicolumn{2}{|c|}{$95 \%$ Cl } \\
\cline { 5 - 7 } & & & & & LCI & HCI \\
\hline \multirow{2}{*}{ EF } & \multirow{2}{*}{ MR } & High & -0.297 & 0.089 & -0.472 & -0.121 \\
& & Low & -0.088 & 0.084 & -0.253 & 0.077 \\
\cline { 5 - 7 } & \multirow{2}{*}{ DIF } & & -0.209 & 0.100 & -0.404 & -0.013 \\
\hline
\end{tabular}

$(-0.209,[-0.472,-0.121] ; 0.088,[-0.253,-0.077] ; 0.209$, $[-0.404,-0.013])$. Hence hypothesis 5 was further supported. The moderating plot was shown in Figure 2.

\section{Discussion}

Based on conservation of resource theory and resourcebased theory, this study proposed a theoretical model implicating the impact of employee resilience on organizational resilience, and elaborated the mediation and boundary conditions between the two. We collected multitime point data of different sizes and industries in china mainland to test the model. The results showed that employee resilience has a significant positive impact on organizational resilience; Problem-focused coping and emotion-focused coping played different mediating roles between the two; In addition, managerial resilience moderated the relationship between employee resilience and emotion-focused coping and the mediating role of emotion-focused coping. When the managerial resilience is low, the negative mediating effect of emotion-focused coping is enhanced.

\section{Theoretical Contributions}

By analyzing multi-time points of leader-employee matching data, we tried to explore the influencing path and boundary, and our study makes several contributions to the existing organizational resilience and employee resilience literatures. First, this paper successfully incorporated employee resilience into the mechanism of organizational resilience, explaining the process of employee resilience's influence on organizational resilience. Organizational resilience is the ability of an organization to respond to and adapt to emergencies and adversity events, which may be

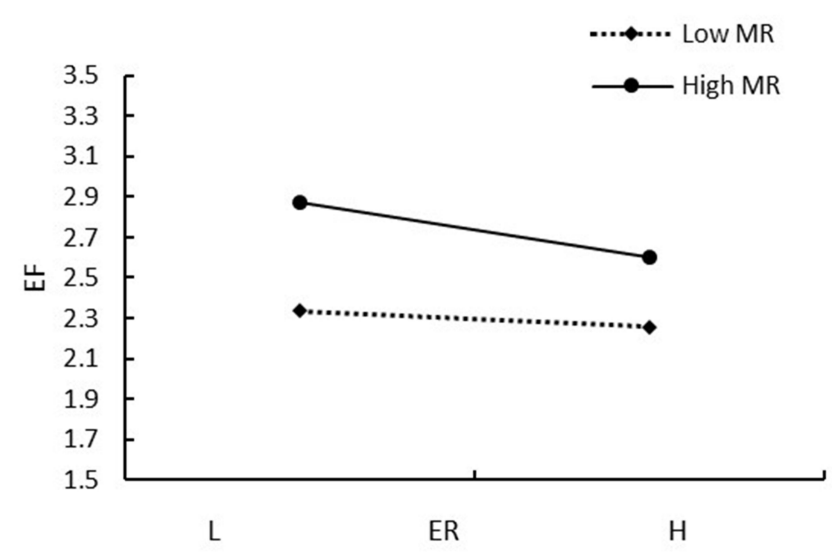

Figure 2 Moderating effect of managerial resilience. 
affected by employees in the same way as other organizational capabilities. ${ }^{66}$ Previous studies have proposed that employee resilience is one of the prerequisites for organizational resilience. ${ }^{10}$ In the Chinese context, ${ }^{50}$ constructed a theoretical framework for strategic human resource management to achieve organizational resilience through employee resilience. Studies have explored the impact of employee resilience on organizational resilience from the perspective of happiness. ${ }^{20}$ Different from previous research perspectives, this research examines the impact of employee resilience from a resource perspective, develops the antecedents of organizational resilience to employee capabilities and behaviors, and provides ideas for the substantive research on the multi-level mechanism of organizational resilience.

Second, based on the conservation of resource theory, individuals have a tendency to strive to acquire, maintain, cultivate and protect their own resources. ${ }^{49}$ Employee resilience is an important content of psychological capital, but it is different from psychological resilience. It emphasizes that employees should respond to adversity based on workplace behavior rather than personal beliefs (). Therefore, this paper comprehensively considers employee resilience, proposes the coping mechanism, and the mediating role of the coping mechanism between employee resilience and organizational resilience. This breaks through previous studies that focused on the meso levels, and focused on the micro level to explore the relationship between employee resilience and organizational resilience; On the other hand, existing research indicates that resources are an important antecedent of organizational resilience, ${ }^{67}$ and resilient employees have more resources. On this basis, this paper further reveals that " resilient employees " with more resources adopts corresponding coping mechanisms to improve organizational resilience in order to achieve resource conservation under the leadership-subordinate framework. This connects the relationship between employee resilience and organizational resilience from the perspective of employee psychology and behavior, and provides more explanation paths for the occurrence of organizational resilience.

Finally, another important theoretical contribution of this research is to incorporate managerial resilience into the employee resilience-organizational resilience relationship. From the perspective of leader-employee interaction, it proposes and examines the moderation effect of managerial resilience on the mediating effect of coping mechanism between employee resilience and organizational resilience. This answers when employee resilience affects organizational resilience through coping mechanisms. Although the leader-member exchange theory has shown that there are complex interactions between leaders and subordinates, ${ }^{68}$ it is not yet fully understood how the combination of leaders and subordinates can enhance employees' cognition and behavior. Existing research regards the exchange of leadership members ${ }^{69}$ and gender combination () as the transition boundary of employee behavior, but rarely pays attention to managerial resilience. Based on this, this paper incorporates managerial resilience into the model of the impact of employee resilience on organizational resilience, and finds that lower managerial resilience turns employee resilience into emotion-focused coping. This not only finds the explanation of manager-employee interaction in organizational resilience, but also realizes the integration of manager-employeeorganizational resilience, and expands the boundary conditions for the occurrence of organizational resilience.

\section{Practical Implications}

Our study has important implications for the management of the organization. First, build a resilient workforce. When employee resilience is aggregated in the organization through double interaction and ASA process, organizational resilience is enhanced and gradually form a resilient homogeneous organization. More specifically, human resource management policies and practices should be aimed at promoting employees' professional knowledge, creativity, and crisis response strategies. Specific training programs and knowledge sharing can be used to improve their capabilities in this area. In addition, companies can also improve employee resilience by organizing crisis response rehearsals and other methods.

Second, strong generals have no weak soldiers. The results highlight the role of managerial resilience in supporting organizational resilience (especially under dynamic and adversity conditions). In this regard, we found that companies that build employee resilience under the guidance of entrepreneurs with strong resilience have higher organizational resilience. Therefore, the managers should be resilient, but this is not enough. They should be able to talk and listen to employees, increase their skills and deliver knowledge and resilient thinking.

Last but not least, openness and inclusiveness, and actively guide. It can be seen from the data that problemfocused coping plays a positive mediate role between employee resilience and organizational resilience, while 
emotion-focused coping is the opposite. Since employees of Chinese companies are more severely affected by the "conventionalism" ideology, they are accustomed to passively accepting rather than proactively attacking. Therefore, in the practice of organization and management, we should pay more attention to the response and guidance of employees, tolerate their active behavior, actively guide employees to establish a spirit of facing difficulties, create a relaxed and tolerant corporate culture atmosphere, and guide employees to diverge thinking.

\section{Limitations and Further Directions}

Inevitably, there are still some limitations of the study, which urgently need to be explored in future research: First, the finding shows that employee resilience can inhibit organizational resilience through emotion-focused coping, but we do not divide emotional attributes (positive or negative). Therefore, follow-up research can explore the impact of emotion on organizational resilience from the positive and negative aspects. Second, although this study uses multipoint data, there is still a certain homology variance problem. It is recommended to improve the research to reduce the impact of the homology variance on the conclusions with experiment or other methods.Third, the study proposes the influence path and boundary of employee resilience on organizational resilience, but employee resilience can be improved through organizational human resource management practices. For this reason, future research can explore the impact mechanism of organizational resilience from the perspective of human resource management practices.

\section{Ethics Statement}

This study was reviewed and approved by the Shandong University of Finance and Economics Ethics Committee. We declare that participants in our research study allow us to use their data for academic research and publication. All the participants were anonymous and their data was protected. All participants provided informed consent and this study was conducted in accordance with the Declaration of Helsinki.

\section{Funding}

This research was funded by the Provincial Natural Science Foundation of Shandong [Grant No. ZR2020MG026].

\section{Disclosure}

The authors declare no conflicts of interest in this work.

\section{References}

1. Branicki LJ, Sullivan-Taylor B, Livschitz SR. How entrepreneurial resilience generates resilient SEMs. Int J Entrepreneurial Behav Res. 2018;24(7):1244-1263. doi:10.1108/IJEBR-11-2016-0396

2. Santoro G, Messeni-Petruzzelli A, Giudice MD. Searching for resilience: the impact of employee-level and entrepreneur-level resilience on firm performance in small family firms. Small Bus Econ. 2020;57:455-471. doi:10.1007/s11187-020-00319-x

3. Chen $\mathrm{CHH}$, Liu $\mathrm{ZH}$. Water-form organizations: a new organizational concept. Foreign Econ Manag. 2017;39(7):3-14. doi:10.16538/j.cnki. fem.2017.07.001

4. Zhao J. Organizational immunity: how to move from fragility to resilience. Tsinghua Bus Rev. 2020;6:101-107.

5. Lengnick-Hall CA, Beck TE, Lengnick-Hall ML. Developing a capacity for organizational resilience through strategic human resource management. Hum Resour Manag Rev. 2011;21 (3):243-255. doi:10.1016/j.hrmr.2010.07.001

6. Sutcliffe KM, Vogus TJ. Organizing for Resilience. In: Cameron KS, Dutton JE, Quinn RE, editors. Positive Organizational Scholarship: Foundations of a New Discipline. San Francisco: Berrett-Koeller; 2003:94-110.

7. Gittell JH, Cameron K, Lim S, Rivas V. Relationships, layoffs, and organizational resilience, airline industry responses to September 11. J Appl Behav Sci. 2006;42(3):300-329. doi:10.1177/0021886306286466

8. Duchek S. Growth in the face of crisis: the role of organizational resilience capabilities. Acad Manag Annual Meet Proc. 2014; (1):13487. doi:10.5465/AMBPP.2014.225

9. Linnenluecke M, Griffiths A. Beyond adaptation: resilience for businessin light of climate change and weather extremes. Bus Soc. 2010;49(3):477-511. doi:10.1177/0007650310368814

10. Fang SE, Prayag G, Ozanne LK, de Vries H. Psychological capital, coping mechanisms and organizational resilience: insights from the 2016 Kaikoura earthquake, New Zealand. Tour Manag Perspect. 2020;34:100637. doi:10.1080/13683500.2019.1607832

11. Chowdhury M, Prayag G, Orchiston C, Spector S. Postdisaster social capital, adaptive resilience and business performance of tourism organizations in Christchurch, New Zealand. J Travle Res. 2019;58 (7):1209-1226. doi:10.1177/0047287518794319

12. Jia X, Chowdhury M, Prayag G, Chowdhury MM. The role of social capital on proactive and reactive resilience of organizations post-disaster. Int $J$ Disaster Risk Reduct. 2020;48:101614. doi:10.1016/j.ijdrr.2020.101614

13. Manfield RC, Newey LR. Resilience as an entrepreneurial capability: integrating insights from a cross-disciplinary comparison. Int $J$ Entrepreneurial Behav Res. 2018;24(7):1155-1180. doi:10.1108/IJEBR-11-2016-0368

14. Zhang XE, Li MY. Research on the driving factors of entrepreneurial resilience and its influence on entrepreneurial success. Foreign Econ Manag. 2020;42(08):96-108. doi:10.16538/j.cnki.fem.20200519.401

15. Ma Z, Xiao L, Yin J. Toward a dynamic model of organizational resilience. Nankai Bus Rev Int. 2018;9(3):246-263. doi:10.1108/ NBRI-07-2017-0041

16. Rabenu E, Tziner A. Employee resilience: a faceted analytical approach. Ind Organ Psychol. 2016;9(2):480-485. doi:10.1017/ iop. 2016.43

17. Andersson T, Cäker M, Tengblad S, Wickelgren M. Building traits for organizational resilience through balancing organizational structures. Scand J Manag. 2019;35(1):36-45. doi:10.1016/j. scaman.2019.01.001

18. Sajko M, Boone C, Buyl T, Greed CEO, Responsibility CS. Organizational resilience to systemic shocks. J Manage. 2020;47 (4):014920632090252. doi:10.1177/0149206320902528

19. Duan SS, Chi YM, Zhang YM. Power of faith: the influence of craftsman spirit on organizational resilience. Foreign Econ Manag. 2021;43(3):57-71. doi:10.16538/j.cnki.fem.10201102.102 
20. Prayag G, Spector S, Orchiston C, Chowdhury M. Psychological resilience, organizational resilience and life satisfaction in tourism firms: insights from the Canterbury earthquakes. Curr Issues Tour. 2020;23(10):1216-1233. doi:10.1080/13683500.2019.1607832

21. Finkelstein S, Hambrick DC. Top-management-team tenure and organizational outcomes: the moderating role of managerial discretion. Adm Sci Q. 1990;35(3):484-503. doi:10.2307/2393314

22. Bullough A, Renko M. Entrepreneurial resilience during challenging times[J]. Bus Horiz. 2013;56(3):343-350. doi:10.1016/j. bushor.2013.01.001

23. Ayala JC, Manzano G. The resilience of the entrepreneur. Influence on the success of the business. A longitudinal analysis. $J$ Econ Psychol. 2014;42(jun):126-135. doi:10.1016/j.joep.2014.02.004

24. Fisher R, Maritz A, Lobo A. Does individual resilience influence entrepreneurial success. Acad Entrepreneurial J. 2016;22(2):39-53.

25. Judge TA, Piccolo RF, Kosalka T. The bright and dark sides of leader traits: a review and theoretical extension of the leader trait paradigm. Leadersh Q. 2009;20(6):855-875. doi:10.1016/j.leaqua.2009.09.004

26. Nguyen Q, Kuntz JRC, Naswall K, Malinen S. Employee resilience and leadership styles: the moderating role of proactive personality and optimism. NZ J Psychol. 2016;45.

27. Avey JB, Luthans F, Jensen SM. Psychological capital: a positive resource for combating employee stress and turnover. Hum Resour Manage. 2009;48(5):677-693. doi:10.1002/hrm.20294

28. Tonkin K, Malinen S, Naswall K, Kuntz JC. Building Employee resilience through wellbeing in organizations. Human Red Dev Quart. 2018;29(2):107-124. doi:10.1002/hrdq.21306

29. Wang J, Cooke FL, Huang W. How resilient is the (future) workforce in China? A study of the banking sector and implications for human resource development. Asia Pacific J Human Res. 2014;52:132-154. doi:10.1111/1744-7941.12026

30. Luthans F, Avey JB, Avolio BJ, Norman SM, Combs GM. Psychological capital development: toward a micro-intervention. J Organ Behav. 2006;27(3):387-393. doi:10.1002/job.373

31. Bardoel EA, Pettit MT, De Cieri H, McMillan L. Employee resilience: an emerging challenge for HRM. Asia Pacific J Human Res. 2014;52(3):279-297. doi:10.1111/1744-7941.12033

32. Luthans $F$. The need for and meaning of positive organizational behavior. J Organ Behav. 2002;23(6):695-706. doi:10.1002/job.165

33. Burnard K, Bhamra R, Tsinopoulos C. Building organizational resilience: four configurations. IEEE Trans Eng Manage. 2018;65 (3):351-362. doi:10.1109/TEM.2018.2796181

34. Coutu DL. How resilience works. Harv Bus Rev. 2002;80(5):46-56. doi:10.2469/faj.v58.n3.2544

35. Lengnick-Hall CA, Beck TE. Beyond bouncing back: the concept of organizational resilience. 2003.

36. Smit B, Wandel J. Adaptation, adaptive capacity and vulnerability. Glob Environ Change. 2006;16(3):282-292. doi:10.1016/j. gloenvcha.2006.03.008

37. Lee AV, Vargo J, Seville E. Developing a tool to measure and compare organizations' resilience. Nat Hazard Rev. 2013;14 (1):29-41. doi:10.1061/(ASCE)NH.1527-6996.0000075

38. Al-Ayed SI. The impact of strategic human resource management on organizational resilience: an empirical study on hospitals. Bus Theory Pract. 2019;20:179-186. doi:10.3846/btp.2019.17

39. Collins JC. Built to last: successful habits of visionary companies. Long Range Plann. 1997;30(1):98-99. doi:10.1016/S0024-6301(97) 86593-4

40. Freeman SF, Maltz M, Hirschhorn L. The power of moral purpose: Sandler O'Neill and partners in the aftermath of September 11, 2001. Organ Dev J. 2004b;22(4):69-82.

41. Thomas JB, Clark SM, Gioia DA. Strategic sensemaking and organizational performance: linkages among scanning, interpretation, action, and outcomes. Acad Manage J. 1993;36:239-271.
42. Hillmann J, Guenther E. Organizational resilience: a valuable construct for management research? Int J Manag Rev. 2021;23(1):7-44. doi:10.1111/ijmr.12239

43. Duchek S. Organizational resilience: a capability-based conceptualization. Bus Res. 2020;13:215-246. doi:10.1007/s40685-019-0085-7

44. Zhu Y, Wang XF, Sun N, Li YJ. Applying strategic human resources management in the study of organizational resilience. Manage Rev. 2014;26(12):78-90. doi:10.14120/j.cnki.cn11-5057/f.2014.12.009

45. Linnenluecke MK. Resilience in business and management research: a review of influential publications and a research agenda. Int J Manag Rev. 2017;19(1):4-30. doi:10.1111/ijmr.12076

46. Folkman S, Lazarus RS, Gruen RJ, Delongis A. Appraisal, coping, health status, and psychological symptoms. J Pers Soc Psychol. 1986;50(3):571-579. doi:10.1037/0022-3514.50.3.571

47. Tang D, Xu Y. The effects and mechanism of coping style and social networks on depressive symptoms among left-behind elderly in rural China. Popul Res. 2019;43(5):54-65.

48. Baker JP, Berenbaum H. Emotional approach and problem-focused coping: a comparison of potentially adaptive strategies. Cogn Emot. 2007;21(1):95-118. doi:10.1080/02699930600562276

49. Hobfoll SE. Conservation of resources. a new attempt at conceptualizing stress. Am Psychol. 1989;44(3):513. doi:10.1037/0003066x.44.3.513

50. Latack JC, Havlovic SJ. Coping with job stress: a conceptual evaluation framework for coping measures. J Organ Behav. 2010;13 (5):479-508. doi:10.1002/job.4030130505

51. Dahles H, Susilowati TP. Business resilience in times of growth and crisis. Ann Tour Res. 2015;51(3):34-50. doi:10.1016/j.annals.2015.01.002

52. Kuijer RG, Marshall EM, Bishop AN. Prospective predictors of short-term adjustment after the Canterbury earthquakes: personality and depression. Psychol Trauma. 2014;6(4):361-369. doi:10.1037/ a0034591

53. Connor KM, Davidson JR. Development of a new resilience scale: the Connor-Davidson resilience scale (CD-RISC). Depress Anxiety. 2003;18(2):76-82. doi:10.1002/da.10113

54. Awotoye Y, Singh RP. Entrepreneurial resilience, high impact challenges, and firm performance. J Manag Policy Pract. 2017;18 (2):28-37.

55. Kobasa SC, Maddi SR, Kahn S. Hardiness and health: a prospective study. J Pers Soc Psychol. 1982;42(1):168. doi:10.1037/00223514.42.1.168

56. Reinmoeller P, van Baardwijk N. The link between diversity and resilience. MIT Sloan Manag Rev. 2005;46(4):60-65. doi:10.1111/ j.1467-8691.2004.00294

57. Wang L, Yang Y, Wang L, Zhao Y. The influence mechanisms of managerial resilience on the common perceptions of corporates and employees. Chin J Manag. 2019;16(06):857-866.

58. Suppiah V, Singh Sandhu M. Organisational culture's influence on tacit knowledge-sharing behaviour. $J$ Zhejiang Univ. 2011;41 (3):462-477. doi:10.1108/13673271111137439

59. Hayward ML, Forster WR, Sarasvathy SD, Fredrickson BL. Beyond hubris: how highly confident entrepreneurs rebound to venture again. J Bus Ventur. 2010;25(6):569-578. doi:10.1016/j.jbusvent.2009.03.002

60. Luthans F, Avolio BJ, Avey JB, Norman SM. Positive psychological capital: measurement and relationship with performance and satisfaction. Pers Psychol. 2007;60(3):541-572. doi:10.1111/j.17446570.2007.00083.x

61. Sinclair VG, Wallston KA. The development and psychometric evaluation of the brief resilient coping scale. Assessment. 2004;11 (1):94-101. doi:10.1177/1073191103258144

62. Kim Y J, Kim J. Does Negative Feedback Benefit (or Harm) Recipient Creativity? The Role of the Direction of Feedback Flow [J]. The Academy of Management Journal. 2020;63(2):584-612. doi:10.5465/amj.2016.1196 
63. Kluger A, Denisi A. The Effects of Feedback Interventions on Performance: A Historical Review, a Meta-Analysis, and a Preliminary Feedback Intervention Theory[J]. Psychological Bulletin. 1996;119(2):254-284. doi:10.1037/0033-2909.119.2.254

64. Strutton D, Lumpkin JR. Problem- and emotion-focused coping dimensions and sales presentation effectiveness. J Acad Market Sci. 1994;22(1):28. doi:10.1177/0092070394221003

65. Aiken LS, West SG. Multiple Regression: Testing and Interpreting Interactions[M]. Newsbury Park, CA: Sage. 1991.

66. Tang YH, Zhao $\mathrm{CH}$, Mao JH, Ding ZK. The relationship between employees' proactive behavior and their innovation performance: the perspective of status competition. Sci Res Manag. 2021;42(3):191-200.
67. Tognazzo A, Gubitta P, Favaron SD. Does slack always affect resilience? A study of quasi-medium-sized Italian firms. Entrep Reg Dev. 2016;28(9-10):768-790. doi:10.1080/08985626.2016.1250820

68. Ridgeway CL. Gender, status, and leadership. J Soc Issues. 2001;57 (4):637-655. doi:10.1111/0022-4537.00233

69. Teng F. The impact of person-organization fit on the procrastination of new researchers - an integrated model. Soft Sci. 2020;34(5):82-87. doi:10.13956/j.ss.1001-8409.2020.05.13

\section{Publish your work in this journal}

Psychology Research and Behavior Management is an international, peer-reviewed, open access journal focusing on the science of psychology and its application in behavior management to develop improved outcomes in the clinical, educational, sports and business arenas. Specific topics covered in the journal include: Neuroscience, memory and decision making; Behavior modification and management; Clinical applications; Business and sports performance management; Social and developmental studies; Animal studies. The manuscript management system is completely online and includes a very quick and fair peer-review system, which is all easy to use. Visit http://www. dovepress.com/testimonials.php to read real quotes from published authors.

Submit your manuscript here: https://www.dovepress.com/psychology-research-and-behavior-management-journal 